5. Raoult D, Brouqui P, Roux V. A new spotted-fever-group rickettsiosis. Lancet. 1996;348:412.

6. Pretorius AM, Birtles RJ. Rickettsia mongolotimonae infection in South Africa. Emerg Infect Dis. 2004;10:125-6.

7. Yu X, Fan M, Xu G, Liu Q, Raoult D. Genotypic and antigenic identification of two new strains of spotted fever group rickettsiae isolated from China. J Clin Microbiol. 1993;31:83-8.
8. Parola $\mathrm{P}$, Inokuma $\mathrm{H}$, Camicas J-L, Broqui P, Raoult D. Detection and identification of spotted fever group rickettsiae and ehrlichiae in African ticks. Emerg Infect Dis. 2001;7:1014-7.

9. Mediannikov OY, Sidelnikov Y, Ivanov L, Mokretsova E, Fournier PE, Tarasevich I, et al. Acute tick-borne rickettsiosis caused by Rickettsia heilongjiangensis in Russian Far East. Emerg Infect Dis. 2004;10: 810-7.
10. Brouqui P, Harle JR, Delmont J, Frances C, Weiller PJ, Raoult D. African tick-bite fever. An imported spotless rickettsiosis. Arch Intern Med. 1997;157:119-24.

Address for correspondence: David H. Walker, The Carmage and Martha Walls Distinguished University Chair in Tropical Diseases, Department of Pathology, Center for Biodefense and Emerging Infectious Disease, University of Texas Medical Branch, 301 University Blvd, Keiller Bldg, Galveston, TX 77555-609, USA; email: dwalker@utmb.edu

ANOTHER DIMENSION

\title{
The Same Air
}

\section{Al Zolynas}

—for Guy Murchie, The Seven Mysteries of Life

The same air

that moves

through me and you

through the waving branches

of the bronchial tree

through veins

through the heart

the same air

that fills balloons

that carries voices

full of lies and truths

and half-truths

that holds up the wings of butterflies

humming birds eagles hang gliders $747 \mathrm{~s}$

the same air

that sits like a dull relative

on humid lakes

in Minnesota in summer

the same air

trapped in vintage champagne

in old bicycle tires lost tennis balls

the air inside a vial in a sarcophagus

in a tomb in a pyramid

buried beneath the sand

the same air inside your freezer

wrapping its cold arms

around your t.v. dinners

the same air that supports you

that supports me

the same air that moves through us

that we move through

the same air frogs croak with

cattle bellow with

monks meditate with and on

the same air we moan with

in pleasure or in pain

the breath I'm taking now

will be in China in two weeks

my lungs have passed an atom

of oxygen that passed through the lungs

of Socrates or Plato

or Lao-tsu or Buddha

or Walt Disney or Ronald Reagan

or a starving child in Somalia

or certainly you

you right here right now

yes certainly you

the same air

the very same air

Zolynas' books include The New Physics, Wesleyan University Press, 1979; Under Ideal Conditions, Laterthanever Press, 1994 (San Diego Book Award, Best Poetry, 1994); and The Same Air, Intercultural Studies Forum, 1997. Seven of his poems were recently featured in the movie Fighting Words (Indican Pictures, Los Angeles, 2007). A long-time Zen practitioner, he teaches at Alliant International University, San Diego, California, and lives with his wife in Escondido, California. 